\title{
Analysis on the Development Strategy of Reverse Logistics in Xiamen
}

\author{
Li Yang \\ Department of Logistics Management \\ Fuzhou University of International Studies and Trade \\ Fuzhou, P. R. China
}

\author{
Dan Liu \\ Department of Logistics Management \\ Fuzhou University of International Studies and Trade \\ Fuzhou, P. R. China
}

\begin{abstract}
Reverse logistics play an important role in the real economic life, mainly by increasing the material repeat utilization rate to reduce production costs. Efficient reverse logistics can ensure the timeliness of goods returned, increase customer purchase experience and the market share. Based on the development of Xiamen reverse logistics, this paper makes some researches on the reverse logistics systems construction, and carries on the mpirical analysis taking the Tetra Pak as the example, provide a reference for development of reverse logistics in Xiamen and even the whole country.
\end{abstract}

\section{Keywords-Xiamen; reverse logistics; Tetra Pakage}

\section{INTRODUCTION}

As a coastal open city, Xiamen's logistics industry plays a decisive role in the national economy. The city's logistics industry actively adjusts the industrial structure during stable and rapid development. The total scale of social logistics continues to expand, and the coefficient of logistics demand improves sustainably. According to the statistics of 2017 Xiamen Special Economic Zone Yearbook, the total revenue of the city's logistics industry exceeded 100 billion yuan for the first time in 2016, an increase of $10 \%$ over the previous year; the industrial added value reached 38 billion yuan, an increase of $7 \%$ over the previous year. The results were included in the national modern logistics innovation development city and intelligent logistics city pilot, and the logistics innovation development sped up. At the same time, the professional logistics center in Xiamen, such as home, building materials, renewable resources and recycled products, has played a very good project driving and service function after their operation, which makes Xiamen's logistics infrastructure equipment more perfect and drive the development of reverse logistics in Xiamen.

\section{PROBLEMS IN THE DEVELOPMENT OF REVERSE LOGISTICS IN XIAMEN}

\section{A. The Overall Economic Scale of Xiamen Is Not Massive, and the Economic Hinterland Is Relatively Small}

Xiamen's economy is relatively backward compared with the Yangtze River Delta, the Pearl River Delta and other regions. Its GDP in Fujian province also ranks behind Fuzhou and Quanzhou. At the same time, restricted by the industrial components in the surrounding areas, the development level of the economic hinterland is limited, causing the development of the reverse logistics in Xiamen to be objectively hindered.

\section{B. Lack of Professional Talents Related to Reverse Logistics in Xiamen}

The relative lack of professional talents related to reverse logistics in Xiamen is a hindrance to the development of reverse logistics in Xiamen. The main reason includes lagging policy related to reverse logistics talents lags behind, imperfect professional reverse logistics personnel training system and low talent demand fitness.

\section{The Logistics Infrastructure in Xiamen Restricts the Development of Reverse Logistics}

Although the construction of transportation infrastructure such as the number of bridges and the length of roads in Xiamen has been continuously improved in recent years, the obstruction of the Wuyi Mountains have caused the inefficient transportation of Fujian railways and the unbalanced development of the economic cooperation zones in Fujian Province.

\section{The "Bottleneck" Situation in the Collection of Reverse Logistics Information in Xiamen Is Highlighted}

It is relatively simple to collect information on used products, by-products, and products that are no longer used in Xiamen. The expired products and the products that are no longer used have been processed by the manufacturing enterprises, and then transported to the consumers, so that the information related to the use of the products is not easy to collect as shown in "Fig. 1". 


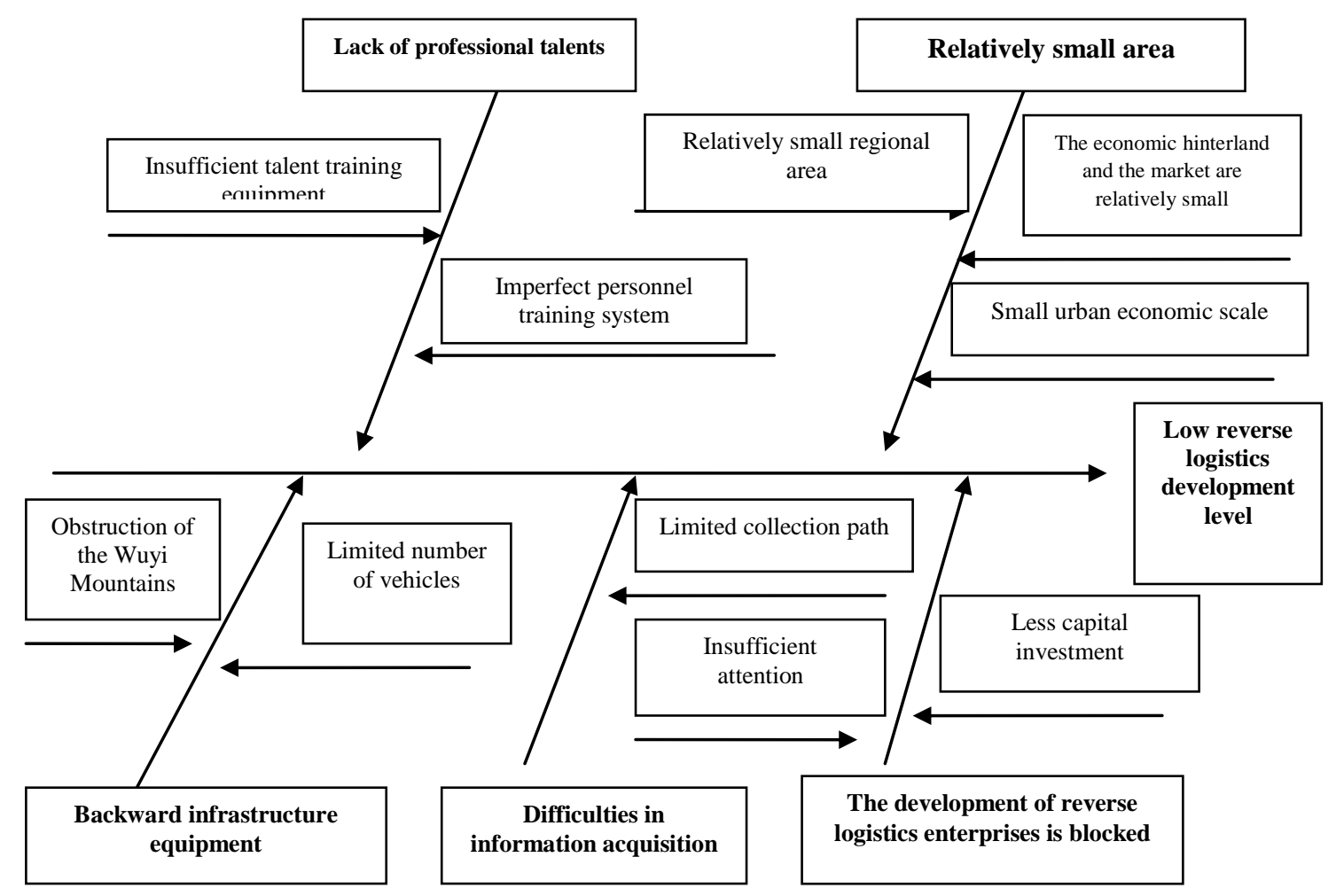

Fig. 1. Fishbone chart of problems in the development of reverse logistics in Xiamen.

\section{THE CONSTRUCTION OF REGIONAL REVERSE LOGISTICS SYSTEM IN XIAMEN}

\section{A. Construction Principle}

1) Systematization of reverse logistics objectives: Based on basic system theory, various elements mutually coordinate and exclude each other in a system, just as the reverse logistics system. The local development affects the overall development. This requires that the subsystems under each reverse logistics system and reverse logistics system of Xiamen have the same strategic objectives to complement each other's advantages and promote the coordinated development of the reverse logistics of each subsystem.

2) Seamless interface port of reverse logistics: The seamless logistics interface port refers to the seamless connection through the integration of natural resources, information technology and institutions, by means of unified technical standards, operational specifications and legal norms, to make its business a smooth and uninterrupted whole process.

3) Rapid response of reverse logistics system: The rapid response of reverse logistics means that it can take the improvement of transportation rate, working performance and message spreading speed of reverse logistics as important objectives during the system construction, and adjust and improve the reverse logistics system.

\section{B. Design of Closed Circulation System}

1) Circulation in enterprises: The circulation in the enterprise takes place within the enterprise. As the basis of the reverse logistics system in Xiamen, its existence plays a very important role. Under the positive guidance of the reverse logistics system in Xiamen, many enterprises have changed in a relatively small scope with the help of the original logistics network foundation and driving of economy and interests. The advantage of the circulation system in enterprises lies in lowering cost, easy operation and reducing the cost increased due to transaction. Therefore, Xiamen City should take the small circulation into account at the earliest during the construction of its reverse logistics system.

2) Circulation in the industrial park: Xiamen City has successively completed the construction and planning of logistics parks. These logistics parks have gathered together to form a scale effect, and the industry chain can circulate in logistics parks. In the park, the system can transport enterprise's waste materials, waste and remaining resources to another enterprise for use as raw materials, so that enterprises can complement each other in resources and energy. Each enterprise promotes the formation of a circular organizational structure through the change of the enterprise itself and mutual promotion between enterprises, and has advantages in terms of economic benefits and resource sharing compared with a single enterprise. 
3) Large circulation in the region: As a new way of economic development, regional large circulation can deeply realize the rational use of resources and the protection of the environment in a wide range of areas. The large circulation in the region has advanced science and technology, including enterprises' advanced technologies in resource conservation and environmental protection, and the places that affect the environment of Xiamen can be managed preferentially. Xiamen City will develop towards resource-saving and environment-friendly, thus promoting the upgrading and optimization of Xiamen's reverse logistics system.

\section{Countermeasures for the Development of Regional Reverse Logistics}

1) Establishing a benign recycling mechanism for renewable resources: By means of successful experience of other developed cities and regions, and based on the actual situation of the region in Xiamen, we establish a benign recycling mechanism for renewable resources that is consistent with the current regional economic development level of Xiamen and related to reverse logistics after the analysis and study. The study and formulation must conform to the laws of economic development so as to promote the development of the reverse logistics industry in Xiamen.

2) Improving the importance of enterprises to reverse logistics: Enterprises often invest more resources in forward logistics in actual operations. While for reverse logistics, managers generally do not pay enough attention to it, and often ignore it when formulating enterprise business strategies, and the same condition is also applied to Xiamen. All enterprises in Xiamen City should pay more attention to reverse logistics, and put reverse logistics and the enterprise's strategic position together. In particular, the attitude of enterprise seniors in reverse logistics plays a key role in the implementation of reverse logistics.

3) Establishing a sound management and information system for reverse logistics: Enterprises can standardize the operation of reverse logistics through advanced information management system and operational management system. There are many differences between reverse logistics and forward logistics, and few enterprises will monitor the whole logistics process of reverse logistics. The lack of reverse logistics information system has become an obstruction to the development of reverse logistics, so it is necessary for Xiamen to establish a sound management and information system for reverse logistics.

4) Establishing a mutually beneficial and win-win partnership between enterprises: Enterprises can outsource their own defective reverse logistics related business to other enterprises, and establish a long-term partnership with the third-party reverse logistics enterprise, so as to complement each other's advantages. In this way, it can not only reduce inventory holding costs and related management costs of logistics services, but also make enterprises focus on improving customer satisfaction and enterprise flexibility, so that all parties can benefit from it.

5) Reducing the probability of occurrence of reverse logistics: We must develop production plans based on customer needs. To achieve economies of scale and ignore the reverse logistics will lead to a large amount of waste. We must conduct market research before products production, and predict the quantity and type of products that customers need in a more accurate way, to avoid blindly producing products. At the same time, we must value the quality of our products, lower the number of repairs and reduce the reverse logistics.

\section{AN EMPIRICAL ANALYSIS OF REVERSE LOGISTICS IN XIAMEN}

\section{A. Overview of Reverse Logistics of Tetra Pak}

In the 1950s, Tetra Pak started on the study of external packing of liquid milk. It has successfully become one of the world's largest suppliers of beverages, milk and other packaging products. Till now, Tetra Pak is an international enterprise that not only can provide comprehensive processing facility equipment, packaging and distribution lines, but also provide design plan for liquid food production plants.

Tetra Pak has the following advantages in reverse logistics activities: in network, both surplus in production and returned goods are relatively dispersed and not easy to transport, and the modern recycling network system connects various scattered Tetra points, thus providing convenience for the development of reverse logistics activities. In terms of technologies in processing technology, in addition to the most basic functions of transportation and storage stressed in reverse logistics, Tetra also focuses on the recycling of packages, and implements reverse logistics activities with dexterity, to promote the development of enterprises. In market, Tetra is market-oriented and aims to explore the ability of reverse logistics.

\section{B. Analysis of Problems Existing in the Development of Tetra Pak in Xiamen}

1) The recycling status of Tetra Pak in Xiamen: Since 2004, Tetra Pak has reported its business practices and performance to the public through the annual Sustainability Development Report. In Greater China, from the donation of environmental protecting device made from 4.38 million used milk beverage packages to Shanghai International Tourism and Resort Zone in 2016 to the opening of the Dala Natural Exploration Camp in 2017, Tetra Pak has constantly developed public oriented environmental education in an innovative way. In 2013, the global recycling rate of Tetra packages reached $24.5 \%$, and about 43 billion $250 \mathrm{ml}$ of standard Tetra packages was recycled, an increase of 4 billion packages over the previous year. In China, after the joint efforts of Tetra Pak, related government agencies and partners, the total amount of recycled milk beverage packages after consumption increased to 139 thousand tons, an increase of $23 \%$ over the previous year, which means that about 17 billion $250 \mathrm{ml}$ of standard Tetra packages have been properly 
recycled, equivalent to $41 \%$ of total annual of Tetra China in 2013.

2) Recycling mode of Tetra Pak in Xiamen: Recycling can make up for the intrinsic value of waste packages and loss, and this value can be used for other purposes. Therefore, recycling takes precedence over disposal. At present, the recycling mode of Tetra Pak in Xiamen has two main types:

a) A recycling model centered on the waste recycling station: "Fig. 2" below shows the most common mode of operation in Xiamen's daily life, which takes scavengers as the main body. Scavengers sell waste to waste stations for profit on their own. Subsequently, the waste recycling station resells the materials needed for Tetra Pak at a higher price to the Tetra Pak recycling plant. The Tetra Pak plant will place products that are produced by means of advanced science and technology on the market. In this way, a circulation will be formed.

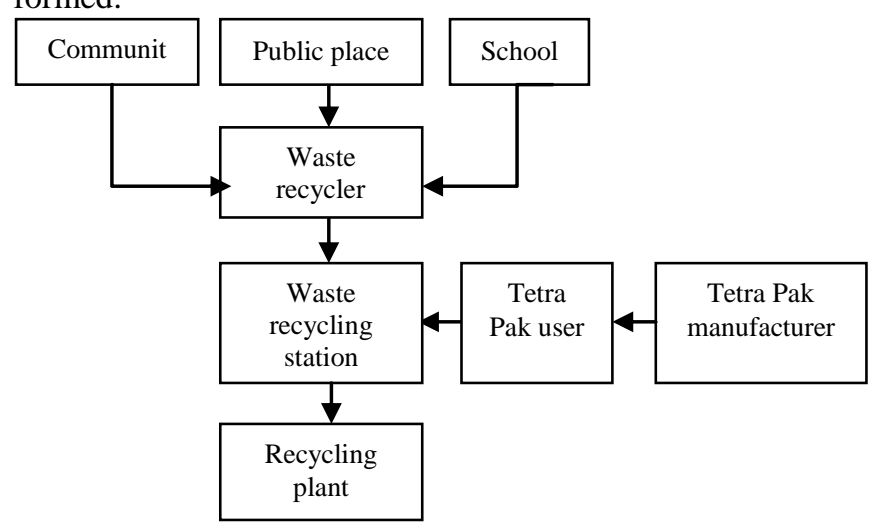

Fig. 2. A model centered on waste recycling.

This mode has the following characteristics:

Advantages: there is no relationship between superior and subordinate, and employment relationship existing in plant, waste recycling station, and the scavengers, which can be adopted by us. The three of them should maintain two-two independence and win-win cooperation. Moreover, the cost of invest in the early stage of recycling is relatively small, and the operational feasibility of this mode is relatively high.

Disadvantages: the most important material of this model comes from the scavengers, which means that the model is carried out around the scavengers. The connection of this model is relatively simple, and market fluctuation is easy to affect its effect. Generally speaking, the price of the single product of Tetra Pak carton is lower than that of the Coke can, resulting in low enthusiasm for recycling and low recycling efficiency. Only by mobilizing the enthusiasm of the scavengers can this model be able to operate at high speed and efficiently.

b) A recycling model centered on waste recycling enterprise: As shown in "Fig. 3", Xiamen has a special recycling enterprise for all kinds of recyclable products. For example, Tetra Pak is based on the enterprise's recycling sites, and buyers can send their own packages of Tetra to the recycling sites. For a part of scattered waste bags, the recycling enterprise can dispatch special staff to uniformly collect and centrally classify them, and the recycling enterprise pays a certain amount of compensation to the waste recycling staff every month.

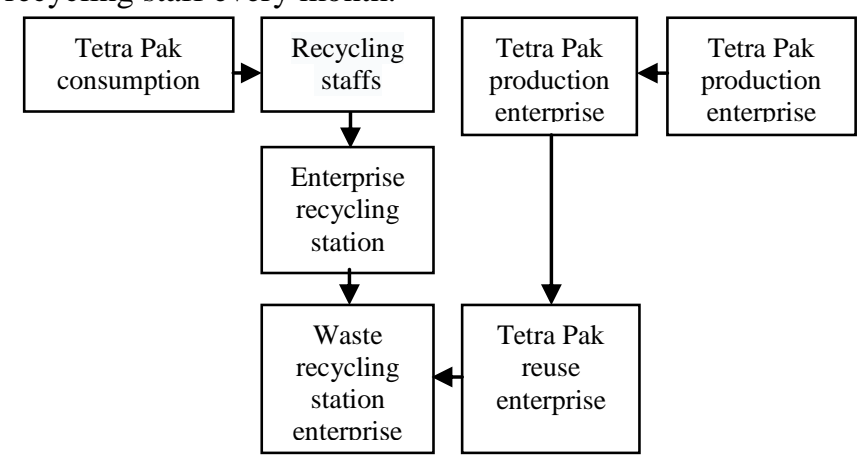

Fig. 3. A model centered on waste recycling enterprise.

After studying the model, it summarizes its following characteristics:

Advantages: its pertinence is more accurate, and the efficiency of recycling staff can be improved. This mode is not very volatile and relatively stable.

Disadvantages: it mainly relies on the buyer's subjective initiative, and the way of waiting for the buyer's delivery to the door is more passive. If the price of Tetra Pak carton is higher than that of other similar competing products, the buyer will be more willing to accept.

Through the research on the two types of recycling models of Tetra packages in Xiamen, it can be concluded that recycling is an important part of reverse logistics, and their goal is to rationally use resources and protect the environment. The returned logistics accounts for a large proportion of reverse logistics. The understanding of recycling logistics, in fact, also is to analyze reverse logistics from the side.

\section{CONCLUSION}

With the rapid development of modern communication systems such as information network technology and the introduction of new business management modes, it provides a convenient condition for the construction of urban reverse logistics system and the organic integration of reverse logistics system with traditional logistics system, and also proposes a larger challenge. From the case analysis, the general principles and norms of the reverse logistics system structure design are summarized. The relationship and interaction of the members in the system are analyzed. And then, it can carry out the optimization and reorganization of the logistics business process, which is of great significance for the research of regional reverse logistics.

\section{REFERENCES}

[1] Wang Ruohan. Enlightenment of Tetra Pak Recycling Model[J]. Recycling of Resources, 2009(1): 36-38. 
[2] Da Qingli, Huang Zuqing, Zhang Qin. Current Situation and Prospect of Research on Reverse Logistics System Structure[J]. China Management Science, 2004(1): 131-138.

[3] Ma Shihua, Lin Yong, Chen Zhixiang. Supply Chain Management [M]. Beijing: Mechanical Industry Press, 2016.

[4] Wang Xiaoling. The Enlightenment of Tetra Pak Industry Chain: Recycling Waste [EB/OL]. http://www.chinanews.com/ny/2011/0719/3192210_3.shtml. 